\title{
Management of predictable pain using fentanyl pectin nasal spray in patients undergoing radiotherapy
}

This article was published in the following Dove Press journal: Journal of Pain Research

10 December 2013

Number of times this article has been viewed

\author{
Brent C Bell \\ E Brian Butler \\ Department of Radiation Oncology, \\ Houston Methodist Hospital, \\ The Texas Medical Center, \\ Houston, TX, USA
}

Correspondence: Brent C Bell Department of Radiation Oncology, Houston Methodist Hospital, I I 30 Earle St, AX 157, Houston, TX 77030, USA $\mathrm{Tel}+$ I 713394 II05

Email bcbell@houstonmethodist.org
Background: Studies report the need for improved pain management in the radiation oncology setting. Many patients with well controlled background pain experience breakthrough pain in cancer (BTPc) that can interrupt their treatment schedule with a potentially negative impact on outcomes. BTPc can be unpredictable and predictable; both types of pain can be managed with fast-acting analgesics, but predictable pain lends itself to anticipatory management.

Methods: Five consecutive cases are described in which fentanyl pectin nasal spray (FPNS) was used to manage BTPc, with an emphasis on the anticipatory management of predictable pain in cancer patients receiving radiotherapy.

Results: Patients (four men, one woman), age range 32-84 years, were diagnosed with various cancers. All patients were receiving opioid treatment for chronic pain, and experienced predictable pain with radiotherapy which included pain associated with lying on a treatment table for a sustained time during an average of 29 radiotherapy treatments; pain associated with radiation simulation and radiotherapy; pain associated with odynophagia related to increasing mucositis during treatment, resulting in decreased nutritional intake; pain associated with the customized immobilization mask for head and neck cancer patients; and pain associated with defecation. Some patients also reported pain awakening them randomly at night (eg, sleep interruption). All patients attained lower pain intensity scores (2/10 to $3 / 10)$, reduced from approximately 7/10, when they were treated with FPNS 20 minutes before a predictable pain event. No patient experienced any pain-related interruptions to their course of radiotherapy. The average number of radiotherapy sessions was 29 per patient, excluding one short-course treatment for one patient.

Conclusion: FPNS offers a good solution to the management of BTPc because its fast onset of action makes it very suitable for the anticipatory treatment of predictable pain, which is likely to minimize interruptions to the radiotherapy schedule.

Keywords: radiotherapy, predictable pain, fentanyl pectin nasal spray, interruption of treatment

\section{Introduction}

More than $50 \%$ of patients with cancer experience pain, which is often of moderateto-severe intensity. In patients with advanced disease, management of pain remains a particular challenge. ${ }^{1}$ A number of guidelines recommend that persistent cancer pain should be managed with around-the-clock treatments, often with a stable dosage of opioids. ${ }^{2-4}$ Despite that treatment, many patients continue to experience acute episodes of severe pain, known as breakthrough pain in cancer (BTPc). BTPc may arise either unpredictably or predictably, possibly triggered by movement, exercise, or some other activity. ${ }^{5}$ 
Recommendations for treatment of BTPc have historically included the addition of a short-acting opioid; however, more recently, guidelines have emphasized the utility of rapid-acting fentanyls. These agents have a rapid onset and short duration of action which match the profile of a typical BTPc episode..$^{2-4}$ Unpredictable episodes of BTPc can only be treated once they arise, but predictable episodes of BTPc create an opportunity to anticipate the pain and pre-emptively treat to reduce or prevent it. $^{2-4}$

Patients undergoing radiotherapy can experience a number of predictable pain situations. In our experience, pain during radiotherapy can include that associated with the need to lie still on a treatment table for a sustained time during radiotherapy or radiation simulation; wearing of the customized immobilization mask for patients with head and neck cancer; odynophagia related to increasing mucositis during radiotherapy; defecation related to development of proctitis; and sleep-interrupting pain that occurs randomly and awakens patients at night (Table 1).

Table I Patient diagnosis and types of predictable pain

\begin{tabular}{|c|c|c|}
\hline Patient & Diagnosis & Types of predictable pain \\
\hline 1 & $\begin{array}{l}\text { Nonkeratinizing squamous } \\
\text { cell carcinoma }\end{array}$ & $\begin{array}{l}\text { - Discomfort of face mask } \\
\text { during RT } \\
\text { - Pain from swallowing due } \\
\text { to mucositis progressing } \\
\text { to grade III } \\
\text { - Pain causing awakening } \\
2-3 \text { times per night }\end{array}$ \\
\hline 2 & $\begin{array}{l}\text { Rectal adenocarcinoma with } \\
\text { lamina propria invasion }\end{array}$ & $\begin{array}{l}\text { - Pain during defecation } \\
\text { - Pain causing night awakening } \\
\text { - Pain from rectal and } \\
\text { perineal irritation }\end{array}$ \\
\hline 3 & $\begin{array}{l}\text { Poorly differentiated } \\
\text { adenocarcinoma of the } \\
\text { head of the pancreas; } \\
\text { lymphovascular and } \\
\text { perineural invasion }\end{array}$ & $\begin{array}{l}\text { - Pain lying on treatment table } \\
\text { during RT } \\
\text { - Mucositis-associated pain } \\
\text { - Pain causing night awakening }\end{array}$ \\
\hline 4 & $\begin{array}{l}\text { Minimally invasive multifocal } \\
\text { low-grade esophageal } \\
\text { adenocarcinoma invading } \\
\text { submucosa; history of } \\
\text { prostate cancer (controlled) } \\
\text { and Parkinson's disease }\end{array}$ & $\begin{array}{l}\text { - Pain on walking and lying } \\
\text { - Pown } \\
\text { - Pain during RT session } \\
\text { - Pain of odynophagia } \\
\text { - Pain on movement and } \\
\text { transfer from wheelchair } \\
\text { to treatment table }\end{array}$ \\
\hline 5 & $\begin{array}{l}\text { Multiple skeletal metastases } \\
\text { from previously treated } \\
\text { urothelial carcinoma }\end{array}$ & $\begin{array}{l}\text { - Left upper arm, shoulder, } \\
\text { and bilateral hip pain } \\
\text { associated with walking and } \\
\text { prolonged sitting } \\
\text { - Pain during RT session }\end{array}$ \\
\hline
\end{tabular}

Abbreviation: RT, radiotherapy.
In a survey conducted in a radiotherapy oncology department, more than half of the patients treated with radiotherapy experienced pain, and 39\% of patients indicated that their pain was inadequately treated. ${ }^{6,7}$ This situation may increase a patient's anxiety and cause them to hesitate, reschedule, or decline radiotherapy treatment. Reasons for radiotherapy treatment interruptions have been poorly described in the literature, perhaps reflecting a lack of awareness of the importance of avoiding interruptions. ${ }^{8}$ One reason that has been reported for treatment interruptions is an inability to withstand the acute side effects of radiotherapy. ${ }^{9,10}$ Such interruptions to the radiotherapy schedule and the associated prolonged overall treatment times can result in loss of local tumor control and an increased risk of tumor repopulation. This phenomenon has been well documented in patients with squamous cell carcinoma of the head and neck, as well as in other cancers. ${ }^{8,11-14}$ The repopulation rate during a treatment gap was estimated to be nearly four times faster than that during irradiation days. ${ }^{15,16}$ One extra day of prolonged treatment of radiotherapy was estimated to reduce local control by $1.4 \%$ to $1.7 \%$ each day. ${ }^{8,17}$ In another study, each day of interruption of radiotherapy was estimated to increase the hazard rate by $3.3 \%$ for local and regional tumor control, and by $2.9 \%$ for disease-free survival. ${ }^{10}$

Predictable BTPc may be particularly associated with the radiotherapy process; there is a need for patients to remain immobile during sessions, in some cases patients need to wear a restraining mask, and radiotherapy can be associated with the development of painful mucositis and proctitis. In those situations in which the pain is predictable, preemptive treatment can be initiated that may allay anxiety and reduce treatment interruptions. While a short-acting opioid could be used, it may need to be administered up to an hour before the event, which is often impractical. ${ }^{2,18}$ By contrast, a rapid-acting fentanyl with a fast onset of action could be given minutes before the anticipated pain. 4,19,20

Fentanyl pectin nasal spray ${ }^{21,22}$ (FPNS, Lazanda ${ }^{\circledR}$ in the US and PecFent ${ }^{\circledR}$ in Europe and Australia) is a nasally administered rapid-acting fentanyl with a fast onset of action that reduces pain within 5 minutes. ${ }^{19,20,23,24}$ Previous studies have shown that intranasally administered FPNS is well accepted by patients; ${ }^{24,25}$ furthermore, the intranasal route avoids the oral cavity which is often compromised in patients with radiotherapy-associated mucositis. As such, FPNS represents a useful tool for the anticipatory management of predictable BTPc. This report presents five consecutive cases (Table 1) in which patients receiving radiotherapy were treated with FPNS for predictable BTPc. Throughout the cases, pain is 
measured by using a $0-10$ scale, where 0 is "no pain" and 10 is "pain as bad as you can imagine". ${ }^{26}$

\section{Case presentations Case I}

A 61-year-old man with a $2.5 \mathrm{~cm}$ invasive, nonkeratinizing, squamous cell carcinoma (T2N2BM0) in the left tonsil region was referred for concurrent chemotherapy and radiation therapy $(6,800$ cGy in 34 fractions with daily sensitizing chemotherapy continued for 7 weeks). Prophylactic supersaturated calcium phosphate oral rinse was used from day 1 , but the patient developed mucositis in week 2 that progressed to grade III by the end of treatment.

At the beginning of treatment, the patient had little pain, but quickly started to experience significant pain especially when swallowing. Long-acting analgesia (hydrocodone/ acetaminophen; $5 / 500 \mathrm{mg}$ increasing to $7.5 / 500 \mathrm{mg}$ every 6-8 hours) was initiated in week 2 , and expanded in week 3 by the addition of fentanyl transdermal patches every 72 hours (initially $25 \mu \mathrm{g}$, later increased to $50 \mu \mathrm{g}$ and then $75 \mu \mathrm{g}$ ). Despite that regimen plus hydrocodone/ acetaminophen 30 minutes before meals, he experienced 6/10 pain with swallowing and awoke $2-3$ times a night with pain that he rated as $7 / 10$. While the long-acting analgesia reduced overall pain, it did not affect the severity of the acute episodes of pain associated with swallowing or the discomfort associated with the need to wear an immobilizing mask during radiotherapy.

FPNS was started in week $5(100 \mu \mathrm{g})$; in particular, the patient was instructed to use FPNS in an anticipatory manner 20 minutes before lunch and dinner, and 20 minutes before radiotherapy sessions. In addition, he used FPNS to treat pain that woke him at night. As an anticipatory treatment, FPNS reduced pain from $8 / 10$ to $3 / 10$. At night, FPNS reduced pain from $6 / 10$ to $2 / 10$, which allowed the patient to return to sleep until the morning. After completion of 34 radiotherapy sessions without interruption, the patient was continued on fentanyl patches ( $75 \mu \mathrm{g}$ every 72 hours) plus FPNS (100 $\mu \mathrm{g} 20$ minutes before meals). By 4 weeks after therapy, the mucositis had resolved sufficiently to allow the oral rinse to be discontinued and the dose of the fentanyl patches to be reduced ( $25 \mu \mathrm{g}$ every 72 hours). By 5 weeks after therapy, the fentanyl patches and FPNS were discontinued.

\section{Case 2}

A 32-year-old man who had a rectal adenocarcinoma with lamina propria invasion (T2N0M0) was referred for combined preoperative therapy with sensitizing capecitabine and intensity-modulated radiation therapy/tomotherapy (cumulative radiation dose of 4,500 cGy over 25 fractions).

His initial pain assessment revealed persistent rectal and low abdominal cramping rated $5 / 10$ occurring $3-4$ times each day and lasting 20-30 minutes. The patient also reported pain during defecation without narcotics (7/10). Hydrocodone/ acetaminophen (10/325 mg four times daily) reduced his defecation pain to $4 / 10$ and cramping abdominal pain to $2 / 10$. During week 2 , the hydrocodone/acetaminophen was increased (two tablets of 10/325 mg every 6 hours) and a fentanyl transdermal patch was added ( $25 \mu \mathrm{g}$ every 72 hours). Because the patient reported nausea within 12 hours of applying the fentanyl patch, ondansetron and lorazepam were prescribed with benefit. During week 4, he reported increased pain with defecation (8/10); in addition, he had a BTPc episode that woke him in the middle of the night $(5 / 10)$. The dose of the fentanyl patch was increased $(50 \mu \mathrm{g}$ every 72 hours), and the hydrocodone/acetaminophen was replaced by FPNS (100 $\mu \mathrm{g} 20$ minutes before defecation). This adjustment reduced pain associated with defecation from $5 / 10$ to a manageable $3 / 10$. Additionally, the night-time pain was reduced from $5 / 10$ to $2 / 10$, which allowed the patient to return to sleep and to remain asleep until morning.

During week 5, the FPNS dose was increased to $200 \mu \mathrm{g}$ as the patient developed radiotherapy-associated rectal and perineal irritation. FPNS reduced the pain from $6 / 10$ to $2 / 10$. The patient continued to complain of nausea (grade II) and the ondansetron was replaced by granisetron transdermal patch that reduced the nausea to grade I. In week 6, the FPNS dose was further increased ( $400 \mu \mathrm{g} 20$ minutes before defecation) which eased the pain associated with defecation to 2/10.

On completion of 25 radiotherapy sessions without interruption, the patient required a further increase in the dosage of the fentanyl patch ( $75 \mu \mathrm{g}$ every 48 hours) because of persistent background pain of 5/10; but by 2 weeks after completing therapy, the fentanyl patch dosage was reduced (first to $50 \mu \mathrm{g}$ and then to $25 \mu \mathrm{g}$ every 72 hours). The FPNS was reduced $(200 \mu \mathrm{g}, 20$ minutes before defecation and during the night if needed). FPNS was discontinued 4 weeks after therapy and the patient was switched back to hydrocodone/ acetaminophen (10/325 mg, up to two tablets every 6 hours) for up to one week prior to discontinuing all narcotics.

\section{Case 3}

A 66-year-old woman, post-Whipple surgery for a moderately to poorly differentiated adenocarcinoma of the head 
of the pancreas with both lymphovascular and perineural invasion (T3N0M0), was referred for combined sensitizing chemotherapy with intensity-modulated radiation therapy/tomotherapy (5,040 cGy over 28 fractions) because her CA-19-9 rose from 4.9 to $581 \mathrm{U} / \mathrm{mL}$ (normal range, 0-35 U/mL).

On referral, the patient complained of diffuse low abdominal pain (7/10). Hydromorphone hydrochloride ( $2 \mathrm{mg}$ every 12 hours) plus hydrocodone/acetaminophen (7.5/500 $\mathrm{mg}$, two tablets every $4-6$ hours) reduced the pain to $5 / 10$. During radiation simulation planning, she complained of abdominal and low back pain while lying on the table (6/10), which persisted for the 40-minute duration of the simulation process. The hydromorphone hydrochloride was discontinued, and FPNS was started (100 $\mu \mathrm{g} 20$ minutes before radiotherapy sessions) and reduced her pain on the table to 2/10. In addition, the patient used FPNS prior to her evening meal to prevent mucositis-associated pain $(5 / 10)$ and once at night when she would awaken with abdominal pain $(7 / 10)$. Her mucositis-associated pain was reduced from $5 / 10$ to $2 / 10$. Her night-time pain was reduced to $3 / 10$, allowing her to return to sleep, which had not been the situation previously. This regimen allowed the patient to complete her 28 planned radiotherapy sessions without interruption.

The patient represented 13 months later when she was referred for stereotactic body radiation $(4,000 \mathrm{cGy}$ in five fractions) because of asymptomatic lung metastases. At that time, her abdominal pain was controlled with intermittent use of hydrocodone/acetaminophen $(7.5 / 500 \mathrm{mg})$ plus FPNS (100 $\mu \mathrm{g}$ as needed, typically once a day and once at night). This regimen controlled her abdominal pain $(3 / 10)$ on most occasions.

After the first radiation treatment to the left lung lesion, the patient experienced stabbing left anterior upper chest pain (7/10); chest computed tomography revealed mediastinal and esophageal compression. A fentanyl transdermal patch was prescribed ( $25 \mu \mathrm{g}$ every 72 hours) and the frequency of FPNS $(100 \mu \mathrm{g})$ was increased to three times a day plus once at night. The patient reported a reduction in her chest pain from $7 / 10$ to $4 / 10$, with alleviation of pain for between 1.5 and 2 hours. Increasing the FPNS dose $(200 \mu \mathrm{g})$ provided greater pain relief $(2 / 10)$.

After completion of stereotactic body radiation, she discontinued the fentanyl patch after 10 days and the FPNS after 12 days. The patient remained on hydrocodone/ acetaminophen (7.5/500 mg, once or twice a day) for slight (3/10) odynophagia.

\section{Case 4}

An 84-year-old man with a minimally invasive, multifocal, low-grade esophageal adenocarcinoma invading into the submucosa was referred for concurrent sensitizing capecitabine chemotherapy with intensity-modulated radiation therapy/ tomotherapy (5,500 cGy over 30 fractions). His medical history included prostate cancer treated with radiation therapy and long-standing but controlled Parkinson's disease.

Upon referral, the patient reported a long history of low back pain (4/10) when walking and when lying down. His background analgesia was hydrocodone/acetaminophen (5/500 mg twice a day) plus a fentanyl transdermal patch (initially $12 \mu \mathrm{g}$, and then $25 \mu \mathrm{g}$ every 72 hours). Because of this pain and the associated Parkinson's disease, he was reluctant to accept the course of radiotherapy. The radiotherapy team suggested a trial of FPNS (100 $\mu$ g given 20 minutes before each session) which managed his discomfort during the 40-minute planning session (3/10). The patient requested better pain control, and the FPNS dose was increased $(200 \mu \mathrm{g}$ 20 minutes before radiation) and further reduced the pain to $2 / 10$, which the patient deemed acceptable. In week 3 , he developed odynophagia $(5 / 10)$ which was reduced to $2 / 10$ by FPNS ( $200 \mu \mathrm{g} 20$ minutes before meals). The patient also experienced reduced rigidity from his neurologic Parkinson's disorder, with improved movement and mobility and decreased pain and anxiety during transfer from wheelchair to treatment table.

The patient completed all 30 radiotherapy sessions without interruption due to pain; he did have a single interruption related to fatigue associated with his Parkinson's disease. Two weeks after completion of radiotherapy, the fentanyl patches were discontinued and the FPNS dose was reduced (100 $\mu \mathrm{g} 20$ minutes before meals). The FPNS was discontinued 4 weeks after completion of therapy.

\section{Case 5}

A 69-year-old man with multiple skeletal metastases from a previously treated high-grade urothelial carcinoma was referred for palliative external beam radiotherapy as pain relief for an upper arm lesion (1,000 cGy over 10 fractions). Despite taking hydrocodone/acetaminophen (7.5/500 mg, two tablets every 6 hours), the patient reported left upper arm and shoulder pain (9/10) as well as bilateral hip pain (5/10) associated with walking and prolonged sitting. Morphine sulfate (15 mg every 4 hours) was added one hour before radiation during which he experienced significant difficulty related to restlessness and pain (6/10 during the entire 40 minutes of simulation, with occasional spikes to 
Table 2 Impact of FPNS on breakthrough pain in cancer in patients receiving $\mathrm{RT}$

\begin{tabular}{llll}
\hline Patient & Predictable pain & $\begin{array}{l}\text { Pain intensity score } \\
(\mathbf{0}-\mathbf{1 0})\end{array}$ \\
\cline { 3 - 4 } & & $\begin{array}{l}\text { Before } \\
\text { treatment }\end{array}$ & $\begin{array}{l}\text { After } \\
\text { FPNS }\end{array}$ \\
\hline I & Pain associated with face mask & 8 & 3 \\
& Pain causing awakening at night & $6-7$ & 2 \\
& Pain with swallowing & 6 & 3 \\
& Pain with defecation & 7 & 2 \\
& Pain causing awakening at night & 5 & 2 \\
& Rectal/perineal pain & 6 & 2 \\
& Pain during RT & 6 & 2 \\
& Postprandial pain & 5 & 2 \\
& Pain causing awakening at night & 7 & 3 \\
4 & Pain during RT & 3 & 2 \\
& Pain during eating & 5 & 2 \\
5 & Pain during RT & 8 & 2 \\
\hline
\end{tabular}

Notes: Pain was reported using a $0-10$ scale, where 0 is "no pain" and 10 is "pain as bad as you can imagine".

Abbreviations: RT, radiotherapy; FPNS, fentanyl pectin nasal spray.

$8 / 10)$. Fentanyl transdermal patches were added ( $25 \mu \mathrm{g}$ every 72 hours) and the morphine was replaced by FPNS (100 $\mu \mathrm{g}$ 20 minutes before radiation). The patient reported grade II nausea and visual hallucinations that resolved when the fentanyl patches were discontinued. Taking hydrocodone/ acetaminophen $(7.5 / 500 \mathrm{mg}$ every $6-8$ hours) plus FPNS (100 $\mu \mathrm{g} 20$ minutes before each session) reduced his pain to $2 / 10$. On this regimen, the patient remained alert and had enough energy to complete all ten sessions without interruption. One week after completion of radiotherapy, the patient discontinued FPNS and remained on hydrocodone/ acetaminophen.

\section{Conclusion and potential implications}

Pain and its management remain a significant challenge in the radiotherapy setting, especially in the management of predictable pain that is associated with the radiotherapy process. In a survey in a radiation oncology department, $39 \%$ of patients reported that their pain was inadequately treated. ${ }^{6,7}$ Such poor pain control has been reported to impact a patient's willingness to attend treatment and to affect their ability to complete a course of treatment without interruptions, which in turn would impact the potential benefits of radiotherapy. ${ }^{8,10-13,15-17,27}$

This case series shows that attention to the patient's reportage and judicious use of long-acting opioids plus a fast-acting analgesic can lead to a significant reduction in pain, particularly predictable episodes of pain. Across this series, pain scores of approximately $7 / 10$ were reproducibly reduced to
2/10 to $3 / 10$ (Table 2) and all patients were able to complete all of their sessions without pain-related interruptions.

The series was limited to five consecutive patients meeting FPNS criteria due to the fact that not all cancer patients require FPNS for BTPc. These groups include the majority of prostate and breast cancer patients treated with radiotherapy. Furthermore, these patients are often not opioid-tolerant. Cost was also a limiting factor regarding noncommercial payers such as Medicare. Hopefully, as others see and respond to our early reporting of this series, more payers will cover FPNS to alleviate BTPc and allow uninterrupted completion of radiotherapy.

The patients presented in this report are typical of those we see in our clinic, experiencing acute exacerbations of chronic pain during radiotherapy sessions in association with positioning on the table and the wearing of uncomfortable immobilizing face masks. In addition, our patients often experience BTPc when eating or defecating because of radiotherapy-induced mucositis or proctitis, respectively. We have found that the use of FPNS for management of BTPc provides both anticipatory relief of predictable pain and the treatment of unpredictable pain (as in patients awakening at night in pain).

FPNS was without difficulty in regard to tapering its use over a 2-4-week period after completion of radiotherapy. Tapering FPNS was simplified in regard to its short-acting and peak response times. Bioavailability and exit of the drug was rapid and there did not appear to be a need for highdose drug escalation in most of the patients in this series. Clinical observation of constipation and lethargy appeared to be decreased overall compared with longer-acting fentanyl which also appeared to require longer tapering intervals in comparison. These experiences suggest that future research with controlled clinical trials would be warranted to better optimize the management of pain in the radiotherapy setting.

\section{Author contributions}

The authors conceived the idea for this article, and were involved in the development of the outline and writing and critical review of drafts. The authors provided and documented cases and data presented for each patient. Both authors read and approved the final draft of the article. The authors gratefully acknowledge Michael Perelman of Archimedes Development Ltd for critical review of the manuscript. Writing and editorial support was provided by Carol Berry, Sharon Suntag, and Julie Gerke from Quintiles Communications and supported by Archimedes Development Ltd. 


\section{Disclosure}

The authors have no conflicts of interest to report.

\section{References}

1. van den Beuken-van Everdingen MH, de Rijke JM, Kessels AG, Schouten HC, van Kleef M, Patijn J. Prevalence of pain in patients with cancer: a systematic review of the past 40 years. Ann Oncol. 2007;18:1437-1449.

2. National Comprehensive Cancer Network: NCCN Clinical Practice Guidelines in Oncology (NCCN Guidelines): Adult Cancer Pain. Version 1.2013. 2013. Available from: http://www.nccn.org/professionals/ physician_gls/f_guidelines.asp. Accessed October 29, 2013.

3. Caraceni A, Davies A, Poulain P, Cortés-Funes H, Panchal J, Fanelli G. Guidelines for the management of breakthrough pain in patients with cancer. J Natl Compr Canc Netw. 2013;11:S29-S36.

4. Caraceni A, Hanks G, Kaasa S, et al. Use of opioid analgesics in the treatment of cancer pain: evidence-based recommendations from the EAPC. Lancet Oncol. 2012;13:e58-e68.

5. Portenoy RK, Hagen NA. Breakthrough pain: definition, prevalence and characteristics. Pain. 1990;41:273-281.

6. Pignon T, Fernandez L, Ayasso S, Durand M, Badinand D, Cowen D. Impact of radiation oncology practice on pain: a cross-sectional survey. Int J Radiat Oncol Biol Phys. 2004;60:1204-1210.

7. Janjan N. Do we need to improve pain management in the radiation oncology department? Nat Clin Pract Oncol. 2005;2:130-131.

8. Garau MM, Monné JS, Serés MJC, Binefa CM, Llopis MP. Compliance to the prescribed overall treatment time (OTT) of curative radiotherapy in normal clinical practice and impact on treatment duration of counteracting short interruptions by treating patients on Saturdays. Clin Transl Oncol. 2009;11:302-311.

9. Chen YP, Tseng NM, Tsang CK, Lin SY. Causes of interruption of radiotherapy in nasopharyngeal carcinoma patients in Taiwan. Jpn $J$ Clin Oncol. 2000;30:230-234.

10. Kwong DL, Sham JS, Chua DT, Choy DT, Au GK, Wu PM. The effect of interruptions and prolonged treatment time in radiotherapy for nasopharyngeal carcinoma. Int J Radiat Oncol Biol Phys. 1997;39: 703-710.

11. Dale RG, Hendry JH, Jones B, Robertson AG, Deehan C, Sinclair JA. Practical methods for compensating for missed treatment days in radiotherapy, with particular reference to head and neck schedules. Clin Oncol. 2002;14:382-393.

12. Coles CE, Burgess L, Tan LT. An audit of delays before and during radical radiotherapy for cervical cancer-effect on tumour cure probability. Clin Oncol. 2003;15:47-54.
13. D’Ambrosio DJ, Li T, Horwitz EM, Chen DYT, Pollack A, Buyyounouski MK. Does treatment interruption affect outcome after radiotherapy for prostate cancer? Int J Radiat Oncol Biol Phys. 2008;72: 1402-1407.

14. Russo G, Haddad R, Posner M, Machtay M. Radiation treatment breaks and ulcerative mucositis in head and neck cancer. Oncologist. 2008;13:886-898.

15. Tarnawski R, Skladowski K, Swierniak A, Wygoda A, Mucha A. Repopulation of tumour cells during radiotherapy is doubled during treatment gaps. J Theor Med. 2000;2:297-305.

16. Tarnawski R, Fowler J, Skladowski K, et al. How fast is repopulation of tumor cells during the treatment gap? Int J Radiat Oncol Biol Phys. 2002;54:229-236

17. Bese NS, Hendry J, Jeremic B. Effects of prolongation of overall treatment time due to unplanned interruptions during radiotherapy of different tumor sites and practical methods for compensation. Int $J$ Radiat Oncol Biol Phys. 2007;68:654-661.

18. Murino P, Mammucari M, Borelli D, et al. Role of immediate-release morphine (MIR) in the treatment of predictable pain in radiotherapy. $J$ Pain Palliat Care Pharmacother. 2011;25:121-124.

19. Fallon M, Reale C, Davies A, et al. Efficacy and safety of fentanyl pectin nasal spray compared with immediate-release morphine sulfate tablets in the treatment of breakthrough cancer pain: a multicenter, randomized, controlled, double-blind, double-dummy multiple-crossover study. J Support Oncol. 2011;9:224-231.

20. Mercadante S. Pharmacotherapy for breakthrough cancer pain. Drugs. 2012;72:181-190.

21. Lazanda ${ }^{\circledR}$ [package insert]. Bedminster, NJ: Archimedes Pharma US Inc; 2012.

22. PecFent ${ }^{\mathbb{\Phi}}$. Summary of Product Characteristics. Nottingham, UK: Archimedes Development Ltd; 2012.

23. Portenoy R, Burton AW, Gabrail N, Taylor D. A multicenter, placebocontrolled, double-blind, multiple-crossover study of fentanyl pectin nasal spray (FPNS) in the treatment of breakthrough cancer pain. Pain. 2010;151:617-624.

24. Portenoy RK, Raffaeli W, Torres LM, et al. Long-term safety, tolerability, and consistency of effect of fentanyl pectin nasal spray for breakthrough cancer pain in opioid-tolerant patients. J Opioid Manag. 2010;6:319-328.

25. Torres LM, Conroy JD, Tayi R, Perelman MS, Knight AD. Assessment of the relationship between ECOG score and fentanyl pectin nasal spray acceptability scores for breakthrough pain in cancer. J Clin Oncol. 2012;30 Suppl:Abstr e19567.

26. Cleeland CS, Ryan KM. Pain assessment: global use of the Brief Pain Inventory. Ann Acad Med Singapore. 1994;23:129-138.

27. Kupelian P. Radiotherapy: effect of treatment interruptions in prostate cancer. Nat Rev Clin Oncol. 2009;6:312-313.
Journal of Pain Research

\section{Publish your work in this journal}

The Journal of Pain Research is an international, peer-reviewed, open access, online journal that welcomes laboratory and clinical findings in the fields of pain research and the prevention and management of pain. Original research, reviews, symposium reports, hypothesis formation and commentaries are all considered for publication.

\section{Dovepress}

The manuscript management system is completely online and includes a very quick and fair peer-review system, which is all easy to use. Visit http://www.dovepress.com/testimonials.php to read real quotes from published authors. 